\title{
Resurgence of fossil fuels?
}

\author{
Subhas K. Sikdar
}

Published online: 20 March 2013

(c) Springer-Verlag Berlin Heidelberg (outside the USA) 2013

The famed Shell Geophysicist M. King Hubbert predicted in the 1950s that oil production in the United States would peak in the 1970s and decline thereafter, creating an ever increasing shortage and consequent dependence on imports to power the increasing societal needs. The facts from the U.S. oil companies quickly confirmed the predicted decline, and Peak Oil became an instantly recognizable moniker to be used in debates about U.S. oil independence and alternative energy. Because of high energy content and portability, petroleum already was a world commodity. Cheap petroleum in global commerce provided mutual benefits to both the exporting nations, many in the developing nations especially in the Middle East, and advanced nations of the West. This symbiosis was shattered in 1973 during the Yom Kippur war when oil was used as a political weapon known as the oil embargo resulting in gasoline shortage and long lines at the gas stations. During regular discourse in political, communication media, and academic circles, words like oil and energy became synonymous. Peak Oil was being confused as Peak Energy. Efforts to aggressively develop alternative sources of energy started in earnest at that time. Peak Oil was a constant inspiration to these efforts. Most of the attention at the time was focused on synthetic fuels via coal gasification and liquefaction. A huge Federal Government spending was undertaken to economically develop variations of the old German Fischer-Tropsch and Bergius processes. These efforts failed, and after the end of the oil embargo, were largely abandoned.

S. K. Sikdar $(\bowtie)$

National Risk Management Research Laboratory, U.S

Environmental Protection Agency, 26 W. M.L. King Dr.,

Cincinnati, OH 45268, USA

e-mail: sikdar.subhas@epa.gov
Then in the 1990s concerns about global warming became greatly intensified with the publication of the first assessment report of the UN Intergovernmental Panel on Climate Change (IPCC), which claimed that the observed warming of the average global temperature was linked to the emission of greenhouse gases from anthropogenic sources, such as power plants, transportation vehicles, and manufacturing facilities. Follow-up reports continued to claim this linkage. The climate models used by the IPCC predicted catastrophic consequences for parts of the Earth in the near future. There is controversy about these predictions and about the adequacy of these models in reliably predicting a very complex system such as the climate. A majority of the governments of the 194-member IPCC countries supported these conclusions and wanted remedial actions through the Kyoto Protocol adopted in 1997. The results have been unsatisfactory and attempts are still underway to regain some momentum on programs on greenhouse gas emission reduction.

Parallel to the Kyoto effort, another concern emanated from the UN-sponsored summit on sustainable development, held first in Rio in 1992, and revisited twice since then. Sustainable development, as the readers of this and other publications would know, is a broader concern than greenhouse effect. Environmental degradation, resource depletion, and intra- and intergenerational equity drove global sustainability agenda. Global warming concerns greatly intensified these concerns. Thus the two movements merged: one to limit greenhouse gases and the other to preserve the environment for societal benefit. Peak Oil was not a major driver anymore for finding fossil alternatives to petroleum.

Interestingly, Peak Oil in the sense of Peak Energy is still being invoked to support the development of nonfossil alternatives such as petroleum. The resource 
depletion part of the sustainable development movement argues for alternatives on the ground that all fossil fuels will be depleted soon and something has to be done to find the energy needed to sustain life and lifestyles. Global warming and environmental concerns, on the other hand, argue that such alternatives must be non-fossil. Research and development is underway worldwide to exploit wind, solar, geothermal, hydropower, nuclear, biomass-based power, and transportation fuels. Despite significant advancements made in three of these, namely wind, solar, and biomass, they still suffer from many deficiencies for competing against the mainstay fossil sources: coal and natural gas. But in recent years, almost suddenly natural gas appeared as a game changer.

Newer technologies, such as hydraulic fracturing and horizontal drilling techniques, have ushered in a gusher of natural gas in Canada and the United States. Unlike petroleum, natural gas is not yet a global commodity and its price is governed by local conditions. Just 3 years ago, natural gas price in the U.S. rose to $\$ 14$ per million BTU, and now because of huge quantities of natural gas being available locally, the price collapsed to about $\$ 3$. Besides, power plants are being renovated to use natural gas in place of coal, causing mine shutdowns and expanded coal export. Other countries around the globe are also exploring this option and will soon find greatly increased use of natural gas palatable.

Natural gas is also a greenhouse gas and will emit carbon dioxide when completely burned. Fugitive emissions in large quantities from these wells, while preventable, can be problematic, if they occur, as the greenhouse effect of methane is 21 times as great as that of carbon dioxide. Economics of natural gas attended by reduced carbon dioxide footprint compared to coal with significant job creation has turned the public opinion in favor of developing these new technologies.

Quite suddenly too, we are in a dilemma. Natural gas reserves that can be exploited by these new technologies in the United States and Canada can meet the energy needs of these countries for many decades, which according to IPCC could be devastating on account of global warming. Similar reserves will undoubtedly be tapped in other countries. Moreover, measures are underway to make liquefied natural gas (LNG) a world commodity. Sustainable development and climate change concerns have met in natural gas a big curious player. Natural gas in large measures helps sustainable development objectives but climate change concerns are not alleviated. Quo Vadis now? Carbon sequestration? It is possible that radical innovations in solar, energy storage, and carbon sequestration technologies deliver a solution. Whether a solution comes in time to save us from the predicted catastrophes is unknowable. If on the other hand, the dire predictions do not come true, would we have not spent a great deal of resources before knowing for sure that the spending is wise? These are questions we will have to think about for years. 